\title{
The use of wearable technology to monitor physical activity in patients with COPD: a literature review
}

This article was published in the following Dove Press journal: International Journal of Chronic Obstructive Pulmonary Disease

\section{Paraskevi Pericleous Tjeerd Pieter van Staa}

Health eResearch Centre, School of Health Sciences, Faculty of Biology, Medicine and Health, The University of Manchester, Manchester MI3 9PL, UK
Correspondence: Tjeerd Pieter van Staa University of Manchester, Vaughan House, Manchester MI3 9GB, UK

Email tjeerd.vanstaa@manchester.ac.uk
Background: Physical activity is an important predictor for survival in patients with COPD. Wearable technology, such as pedometer or accelerometer, may offer an opportunity to quantify physical activity and evaluate related health benefits in these patients.

Objectives: To assess the performance of wearable technology in monitoring and improving physical activity in COPD patients from published studies.

Methods: Literature search of Medline, Cochrane, Dare, Embase and PubMed databases was made to find relevant articles that used wearable technology to monitor physical activity in COPD patients.

Results: We identified 13 studies that used wearable technology, a pedometer or an accelerator, to monitor physical activity in COPD patients. Of these, six studies were randomized controlled trials (RCTs) which used the monitors as part of the intervention. Two studies reported the same outcomes and comparable units. They had measured the difference that the intervention makes on the number of steps taken daily by the patients. The results were highly heterogeneous with $\mathrm{I}^{2}=92 \%$. The random-effects model gave an effect outcome on the number of steps taken daily of $1,821.01$ [-282.71; 3,924.74] in favor of the wearable technology. Four of the 13 studies have reported technical issues with the use of the wearable technology, including high signal-to-noise ratio, memory storage problems and inaccuracy of counts. While other studies did not mention any technical issues, it is not clear whether these did not experience them or chose not to report them.

Conclusions: Our literature search has shown that data on the use of wearable technology to monitor physical activity in COPD patients are limited by the small number of studies and their heterogeneous study design. Further research and better-designed RCTs are needed to provide reliable results before physical activity monitors can be implemented routinely for COPD patients.

Keywords: COPD, physical activity, monitors, wearable

\section{Introduction}

COPD is the fifth leading cause of death worldwide. The epidemic of smoking has been the main contributing factor, responsible for $40-70 \%$ of the COPD cases. ${ }^{1}$ Other highly associated factors are age (over 65 years) and genetics. ${ }^{1}$ It has been found that white ancestry, exposure to air pollution or occupational exposure (dust, traffic exhaust fumes, sulphur dioxide), abnormal lung (childhood infection), male sex and a low socioeconomic status are weaker risk factors associated with COPD. ${ }^{1}$ Patients with COPD usually have other co-morbidities such as cardiovascular 
disease, skeletal muscle dysfunction, metabolic syndrome, osteoporosis, lung cancer and diabetes. ${ }^{1,2}$ Additionally, psychiatric co-morbidities such as depression, anxiety and psychosis are common in COPD patients. ${ }^{2}$ The number of COPD cases is not expected to reduce in the future, ${ }^{1}$ and thus there is a need to find new ways of reducing the burden of COPD.

Physical activity involves the movement of the body caused by the muscles and shown to have health benefits. ${ }^{3}$ COPD decreases the capacity to perform physical activity. ${ }^{4}$ Physical activity is a significant predictor of survival of COPD patients, ${ }^{5}$ but a means to easily monitor and quantify physical activity in COPD patients has been lacking. Current wearable technology, also known as physical activity monitors or trackers, includes pedometers (providing steps over a period of time) and accelerometers (providing counts and/or estimates of energy expenditure). The most commonly used can be adjusted to the arm, waist, wrist, foot or thigh. Some locations (such as the arm) are more comfortable to the user and some others (such as the thigh) give more robust information. The relation between physical activity in COPD patients and their survival has been established, ${ }^{4,5}$ and the measurement of physical activity has thus the potential to be very valuable in routine clinical practice as a feedback and educational tool to improve the condition and survival.

Current wearable technology consists of a device fitted to the participant's body which detects and collects the data and requires access to a computer to retrieve the data. The reliability and validity of data collected depend solely on each individual device. ${ }^{6}$ Practical issues have been reported with physical activity trackers: some can be quite costly and uncomfortable or difficult to wear. Furthermore, the slow motion of patients with limited mobility, such as COPD patients, may not be detected by the sensors. ${ }^{6}$ Also, exercising while remaining static, such as arm movement only and pendulous abdomen movement, may not be measured. Or conversely, movements when it does not belong to the patient, such as the motion of a moving car, may be included. ${ }^{6,7}$ Problems related to adherence and proper usage have been noted by several studies on wearable devices monitoring physical activity (not limited to COPD studies). ${ }^{8-11}$ These include an inconsistency between monitors and self-report questionnaires, likely due to the monitors, not the participants ${ }^{12}$ and a high signal-to-noise ratio. ${ }^{13}$

Exacerbations of COPD leading to hospitalization are associated with a high risk of readmission. ${ }^{14}$ For hospitalized
COPD patients, surrogate markers may be more appropriate instead of physical activity monitors. ${ }^{14}$ Physical frailty (gait speed $<0.8 \mathrm{~m} / \mathrm{s}$ in the $4 \mathrm{~m}$ walk test) is a simple measure of physical performance and able to predict the risk of readmission in older patients who have been hospitalized due to COPD exacerbation. ${ }^{14}$

While frailty is quite common in COPD patients, there is no evidence of an association between COPD and frailty. ${ }^{15}$ Thus, there is a need for an investigation into the effects of frailty on COPD patients, due to the large number affected. ${ }^{15}$ Also, it has recently been suggested that measuring frailty is important for risk stratification of COPD patients and the use of an upper-extremity function test in predicting adverse outcomes has been recommended. ${ }^{16}$

The objective of our literature review was to assess the performance and effects of wearable technologies in COPD patients. We also evaluated any limitations for practical use and considered recommendations for best use of wearable technology in COPD patients.

\section{Methods}

This literature review included randomized controlled trials (RCTs) and observational studies that used wearable technology to monitor physical activity in COPD patients. The studies had to be written in English and published in peer-reviewed journals. We excluded abstracts, protocols, pilot studies, duplicate articles, book chapters, studies not written in English, studies with the patient not being the main actor (eg, validating the technology was the goal of the study), studies that did not use wearable technology or used wearable technology for reasons other than monitoring physical activity (such as self-management of COPD), studies that did not include COPD patients or studies that only validated the technology and studies that evaluated the relation between physical activity and COPD (as this is already established on literature). The studies included in this review concerned COPD patients with severity according to the GOLD criteria ranging from mild to very severe. We also restricted the studies to those that evaluated wearable technology such as pedometers and accelerometers used for the purposes of monitoring physical activity. The primary outcomes that were evaluated in this review included step and activity counts or walk distance in miles as estimated by the monitor and the time spent in exercise. The secondary outcome included any technical and usability issues of the monitors experienced by COPD patients. 


\section{Results}

We identified nine RCTs and four observational studies from this literature search strategy. The duration of the studies varied from $48 \mathrm{hrs}$ to 1 year. Only five of the studies used the monitor as part of the intervention, the others used the device to track physical activity only. The majority quantified physical activity into step counts, activity counts or walk distance. Other studies chose to present the duration (or amount) of time the patients spent in an exercise session.

\section{Primary outcomes (monitor data)}

1. Step count: activity counts or walk distance in miles as found from the monitor

Studies that compared COPD patients with healthy controls found that physical activity in COPD patients was significantly less than in healthy people. There are interventions that increased the counts/distance in COPD patients. ${ }^{17,18}$ However, there are studies that found no difference between the intervention and control groups. ${ }^{13,19}$ Studies that have used the monitors as part of the intervention all found that the intervention group had improved more than the control group. ${ }^{20,21}$

\section{Time spent in exercise session}

The monitors may help COPD patients in spending more time exercising: Hunter et al (2006) found that the COPD patients with monitors spent $103 \%$ more time compared with prescription only groups on each training session. ${ }^{22}$ An intervention managed to increase the time spent exercising, ${ }^{23}$ but another study did not achieve that result. ${ }^{24}$

The primary and secondary outcomes for each of the 13 studies have been tabulated (Table 1); secondary outcome noted technical or utility issues related to the wearable technology.

\section{Forest plots for effect in steps count}

Figure 1 shows the mean difference in the number of daily steps taken by COPD patients using a physical activity monitor compared to those without a control. This analysis was based on only two studies as other studies used different units. ${ }^{20,21}$ These two studies were found to be statistically heterogeneous with Higgin's $I^{2}=92 \%$, which could be due to the monitors and the use of different algorithms and/or differences in their study designs. Using a random-effects model (recommended in case of heterogeneity), the mean improvement in daily steps with a physical activity monitor was $1,821.01$ which was not statistically significant.

\section{Discussion}

This review focused on published studies that reported on the use of wearable technology for monitoring physical activity in COPD patients. Our literature search of electronic databases identified 13 studies. As the majority of studies did not use the same outcomes and units, we could compare only two studies which measured the effect that a physical activity monitor has on the number of steps taken daily by the participants. A random-effects model found that the mean difference in the number of steps was improved in those with monitors, but this was not statistically significant.

Our review has also identified that physical activity monitors will need to become more accurate (insensitive to low walking speeds, altering readings when shaken, memory storage problems, high signal-to-noise ratio) and their placement made more comfortable for the COPD user. ${ }^{13,24-26}$ The effect of the monitor was assessed as an educational and motivational tool on the physical activity in COPD patients. ${ }^{20,24,26}$ More studies are needed to provide a robust analysis of the effectiveness and usability of these technologies. In order to be able to apply such a monitoring system more widely, there is a need for a platform where health care practitioners can monitor live data from the technology and health care professionals need to be trained to communicate better with patients. Some health care organizations recognize the necessity to use technology. ${ }^{29}$ However, a study showed that no strict guidelines have been set by the Department of Health and National Institute for Health and Care Excellence (NICE) for use of clinical technologies. As reported by Llewellyn et al, there is a need to evaluate technologies and an infrastructure to ensure diffusion more widely. ${ }^{30}$ Also, health care professionals will need to be trained in how to use and interpret these technologies. These issues will need to be addressed before these technologies can be used in the health care system.

More studies are needed to assess if a physical activity monitor can enhance physical activity in COPD patients. For now, there are not enough studies, and the few of them that use the monitor as an educational and motivational tool, are highly heterogeneous. Thus, no conclusion can be drawn about the effect that the monitor could have on the physical activity of COPD patients. We believe that such a relationship exists, and 
Table I Summary of the results reported on the use of wearable technology for monitoring physical activity in COPD patients

\begin{tabular}{|c|c|c|}
\hline Study & $\begin{array}{l}\text { Primary outcomes: } \\
\text { I) Step count, Activity counts or walk distance } \\
\text { 2) Time spent in exercise session }\end{array}$ & Secondary outcome: Technical issues and monitor usability \\
\hline Singh et al, $200 \mathrm{I}^{25}$ & $\begin{array}{l}\text { 1) Mean counts and total activity counts while brisk and slow } \\
\text { walking in COPD group was significantly less than healthy } \\
\text { group. }\end{array}$ & Unable to assess upper body movements \\
\hline $\begin{array}{l}\text { Bauldoff et al, } \\
2002^{17}\end{array}$ & $\begin{array}{l}\text { 1) Cumulative distance walked by the intervention group was } 19 \\
\pm 16.7 \text { miles compared to } 15.4 \pm 8.0 \text { miles for the control group }\end{array}$ & N/A \\
\hline $\begin{array}{l}\text { Sewell et al, } \\
2005^{19}\end{array}$ & $\begin{array}{l}\text { 1) Significant statistical improvement in activity counts for } \\
\text { both groups. There was an increase of } 29.18 \% \text { of activity } \\
\text { monitor counts in the control group and } 40.63 \% \text { in the } \\
\text { intervention group }\end{array}$ & $\mathrm{N} / \mathrm{A}$ \\
\hline $\begin{array}{l}\text { Hunter et al, } \\
2006^{22}\end{array}$ & $\begin{array}{l}\text { 1) Counts per minute of exercise sessions was 150\% more } \\
\text { than prescribed (range: } 55-434 \% \text { ) }\end{array}$ & $\begin{array}{l}\text { Errors from a vibrating vehicle movement, poor between } \\
\text { monitor reproducibility }\end{array}$ \\
\hline Steele et al, $2008^{13}$ & $\begin{array}{l}\text { I) No statistically significant accelerometer activity difference } \\
\text { between intervention and control at any time-point }\end{array}$ & High signal-to-noise ratio in sedentary population \\
\hline Moy, $2009^{26}$ & $\begin{array}{l}\text { I) The overall mean steps per day for COPD patients was } \\
2,026 \pm 1,783 \text { (no comparison) }\end{array}$ & $\begin{array}{l}\text { Not accurate at low walking speeds, limited memory storage, } \\
\text { cannot capture extreme activities or energy expenditure }\end{array}$ \\
\hline Effing et al, $2011^{18}$ & $\begin{array}{l}\text { 1) Mean difference in steps between the two groups for the } \\
\text { whole study period was } 877 \text { steps per day in favour of the } \\
\text { intervention } \\
\text { 2) For total activity, the COPD group completed a mean time of } \\
14,838 \pm 7 \text { II } 5 \text { and healthy individuals completed } 24,028 \pm 12399 \text {. }\end{array}$ & N/A \\
\hline Kawagoshi, $2015^{23}$ & $\begin{array}{l}\text { 2) The time spent walking in baseline and I year later chan- } \\
\text { ged more in the intervention group compared with the } \\
\text { control group (intervention: } 51.36 \pm 3.7 \text {, control: } 12.3 \pm 25.5 \text { ). }\end{array}$ & N/A \\
\hline $\begin{array}{l}\text { Mendoza et al, } \\
2015^{20}\end{array}$ & $\begin{array}{l}\text { I) Intervention group had a progressive daily average step } \\
\text { increase throughout the study. The intervention group had } \\
3,080 \pm 3,254 \text { daily steps, while the control group had } 138.3 \\
\pm 1,950 \text { daily steps }\end{array}$ & N/A \\
\hline Moy, $2015^{21}$ & $\begin{array}{l}\text { 1) Patients in the intervention group walked } 779 \text { more steps } \\
\text { per day at } 4 \text { months. They increased significantly their mean } \\
\text { daily step counts by } 447 \text { steps at } 4 \text { months, which was an } \\
\text { increase of } 13 \% \text { from baseline. Patients in the control group, } \\
\text { however, had a decrease of } 346 \text { daily step counts at } 4 \text { months }\end{array}$ & N/A \\
\hline Moy et al, $2016^{27}$ & $\begin{array}{l}\text { I) No significant difference between the two groups (inter- } \\
\text { vention and control) at } 12 \text { months and no significant change } \\
\text { in their daily step count compared to baseline. The inter- } \\
\text { vention group kept daily step counts higher than the baseline } \\
\text { values throughout the study }\end{array}$ & N/A \\
\hline $\begin{array}{l}\text { Iwakura et al, } \\
2016^{28}\end{array}$ & $\begin{array}{l}\text { I) Significantly reduced number of daily steps in the COPD } \\
\text { patients (mean }=4,546, s d=2,992 \text { ) compared to the healthy } \\
\text { control (mean }=8,7 \mid 3, S D=3,480 \text { ) } \\
\text { 2) The time spent daily in moderate-to-vigorous physical } \\
\text { activity from the COPD patients (mean }=\mid 3.9, S D=14.0 \text { ) was } \\
\text { significantly less than the time spent from the healthy control } \\
\text { (mean }=27.4, S D=19.1 \text { ) }\end{array}$ & $\mathrm{N} / \mathrm{A}$ \\
\hline Nolan et al, $2017^{24}$ & $\begin{array}{l}\text { I) The median step-count target for the final week of the } \\
\text { program in patients allocated at the intervention was } 36 \% \\
\text { higher than the baseline step count } \\
\text { 2) The time spent in expending at least } 3 \text { metabolic equiva- } \\
\text { lents (METs) did not differ between the two groups (inter- } \\
\text { vention and control) at } 3 \text { different time-points }\end{array}$ & $\begin{array}{l}\text { Complaints about the location of the pedometer, not picking } \\
\text { up all steps, adding more steps by shaking it, showing invalid } \\
\text { or missing accelerometer data; a patient stopped using it } \\
\text { because he/she was obsessed with the step-count target and } \\
\text { wide data variability }\end{array}$ \\
\hline
\end{tabular}




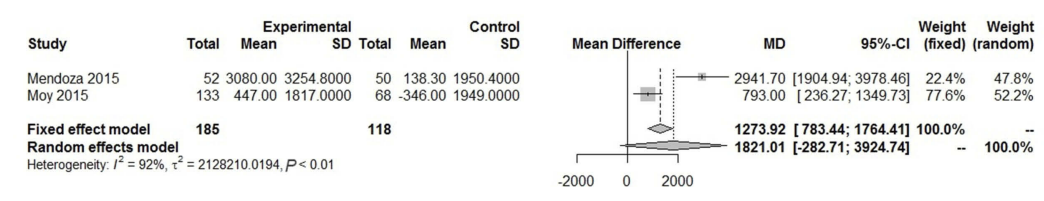

Figure I Forest plot of the mean difference in the number of daily steps in COPD patients using a physical activity monitor compared to those without a monitor as control.

once it is established, the COPD patients can improve physical activity, and thus their survival.

This study has several limitations. Only a small number of studies were identified and these studies were highly heterogeneous, with only two comparable. The results cannot be conclusive and more RCTs are required before making any conclusions.

In conclusion, future research should focus on dealing with monitor issues (memory storage, noise-to-signal ratio, etc.) and more RCTs are required to find the effect of physical activity monitors as part of an exercise intervention for COPD patients. There is a need for more and better studies that estimate the costs and benefits of using these technologies and to develop a strategy that will make this kind of technology sustainable beyond the pilot stage.

\section{Disclosure}

Professor Tjeerd Pieter van Staa reports grants from GSK and personal fees from Pfizer, outside the submitted work. The authors report no other conflicts of interest in this work.

\section{References}

1. Sharifabad MA. COPD. BMJ Best Pract. 2017. Available from: http:// bestpractice.bmj.com/topics/en-gb/7/pdf/7.pdf. [accessed March 23, 2018]. [PMC4076139].

2. Shah T, Press VG, Huisingh-Scheetz M, White SR. COPD readmissions: addressing COPD in the era of value-based health care. Chest. 2016;150 (4):916-926. [PubMed: 27167208]. doi:10.1016/j.chest.2016.05.002

3. Benzo R. Activity monitoring in chronic obstructive pulmonary disease. J Cardiopulm Rehabil Prev. 2009;29:341-347. [PubMed: 99406638]. doi:10.1097/HCR.0b013e3181be7a3c

4. Schonhofer B, Ardes P, Geibel M, Kohler D, Jones PW. Evaluation of a movement detector to measure daily activity in patients with chronic lung disease. Eur Respir J. 1997;10:2814-2819. doi:10.1183/ 09031936.97.10122814

5. Garcia-Aymerich J, Lange P, Benet M, Schnohr P, Anto JM. Regular physical activity reduces hospital admission and mortality in chronic obstructive pulmonary disease: a population-based cohort study. Thorax. 2006;61:772-778. [PubMed: 16738033]. doi:10.1136/ thx.2006.060145

6. Steele BG, Belza B, Cain K, Warms C. Bodies in motion: monitoring daily activity and exercise with motion sensors in people with chronic pulmonary disease. J Rehabil Res Dev. 2003;40(5):45-58. [PubMed: 15074453].
7. O’Connell S, Ólaighin G, Quinlan LR. When a step is not a step! specificity analysis of five physical activity monitors. PLoS One. 2017;12: e0169616. [PubMed: 28085918]. doi:10.1371/journal.pone.0169616

8. Allet L, Knols RH, Shirato K, de Bruin ED. Wearable systems for monitoring mobility-related activities in chronic disease: a systematic review. Sensors. 2010;10:9026-9052. [PubMed: 22163393]. doi: $10.3390 / \mathrm{s} 101009026$

9. Toda Y, Toda T, Takemura S, Wada T, Morimoto T, Ogawa R. Change in body fat, but not body weight or metabolic correlates of obesity, is related to symptomatic relief of obese patients with knee osteoarthritis after a weight control program. $J$ Rheumatol. 1998;25:2181-6. [PubMed: 9818662].

10. Keyserling TC, Samuel-Hodge CD, Ammerman AS, et al. A randomized trial of an intervention to improve self-care behaviors of African-American women with type 2 diabetes: impact on physical activity. Diabetes Care. 2002;25:1576-1583. [PubMed: 12196430]. doi:10.2337/diacare.25.9.1576

11. Lemaster JW, Mueller MJ, Reiber GE, Mehr DR, Madsen RW, Conn VS. Effect of weight-bearing activity on foot ulcer incidence in people with diabetic peripheral neuropathy: Feet First Randomized Controlled Trial. Phys Ther. 2008;88:1385-1398. [PubMed: 18801859]. doi:10.2522/ptj.20080019

12. Hughes AR, Mutrie N, Macintyre PD. Effect of an exercise consultation on maintenance of physical activity after completion of phase III exercise-based cardiac rehabilitation. Eur J Cardiovasc Prev Rehabil. 2007;14:114-121. [PubMed: 17301636]. doi:10.1097/ HJR.0b013e3280116485

13. Steele BG, Belza B, Cain KC, et al. A randomized clinical trial of an activity and exercise adherence intervention in chronic pulmonary disease. Arch Phys Med Rehabil. 2008;89(3):404-412. [PubMed: 18295615]. doi:10.1016/j.apmr.2007.11.003

14. Kon SSC, Jones SE, Schofield SJ, et al. Gait speed and readmission following hospitalisation for acute exacerbations of COPD: a prospective study. Thorax. 2015;70:1131-1137. [PubMed: 26283709]. doi:10.1136/thoraxjnl-2015-207046

15. Marengoni A, Vetrano DL, Manes-Gravina E, Bernabei R, Onder G, Palmer K. The relationship between COPD and frailty: a systematic review and meta-analysis of observational studies. Chest. 2018;154(1):21-40. [PubMed: 29477493]. doi:10.1016/j. chest.2018.02.014

16. Ehsani H, Mohler MJ, Golden T, Toosizadeh N. Upper-extremity function prospectively predicts adverse discharge and all-cause COPD readmissions: a pilot study. Int J Chron Obstruct Pulmon Dis. 2019;14:39-49. [PubMed: 30587960]. doi:10.2147/COPD. S182802

17. Bauldoff GS, Hoffman LA, Zullo TG, Sciurba FC. Exercise maintenance following pulmonary rehabilitation: effect of distractive stimuli. Chest. 2002;122(3):948-954. [PubMed: 12226037]. doi:10.1378/ chest.122.3.948

18. Effing T, Zielhuis G, Kerstjens H, van der Valk P, van der Palen P. Community-based physiotherapeutic exercise in COPD self-management: a randomised controlled trial. Respir Med. 2011;105(3):418-426. [PubMed: 20951018]. doi:10.1016/j. rmed.2011.03.020 
19. Sewell L, Singh SJ, Williams JE, Collier R, Morgan MD. Can individualized rehabilitation improve functional independence in elderly patients with COPD? Chest. 2005;128(3):1194-1200. [PubMed: 16162706]. doi:10.1378/chest.128.3.1194

20. Mendoza L, Horta P, Espinoza J, et al. Pedometers to enhance physical activity in COPD: a randomised controlled trial. Eur Respir J. 2015;45:347-354. [PubMed: 25261324]. doi:10.1183/ 09031936.00084514

21. Moy ML, Collins RJ, Martinez $\mathrm{CH}$, et al. An internet-mediated pedometer-based program improves health-related quality-of-life domains and daily step counts in COPD: a randomized controlled trial. Chest. 2015;148(1):128-137. [PubMed: 25811395]. doi:10.1378/chest.14-1466

22. Hunter J, Singh SJ, Morgan MD. Objective monitoring of adherence with home exercise training during pulmonary rehabilitation for chronic obstructive pulmonary disease. Physiotherapy. 2006;92 (1):50-54. doi:10.1016/j.physio.2005.08.006

23. Kawagoshi A, Kiyokawa N, Sugawara K, et al. Effects of low-intensity exercise and home-based pulmonary rehabilitation with pedometer feedback on physical activity in elderly patients with chronic obstructive pulmonary disease. Respir Med. 2015;109 (3):364-371. [PubMed: 25682543]. doi:10.1016/j.rmed.2015.01.008

24. Nolan CM, Maddocks M, Canavan JL, et al. Pedometer step count targets during pulmonary rehabilitation in chronic obstructive pulmonary disease: a randomized controlled trial. Am J Respir Crit Care Med. 2017;195:1344-1352. [PubMed: 27911566]. doi:10.1164/ rccm.201701-0150WS
25. Singh S, Morgan MD. Activity monitors can detect brisk walking in patients with chronic obstructive pulmonary disease. J Cardiopulm Rehabil. 2001;21:143-148. [PubMed: 19940638]. doi:10.1097/ 00008483-200105000-00004

26. Moy ML, Matthess K, Stolzmann K, Reilly J, Garshick E. Free-living physical activity in COPD: assessment with accelerometer and activity checklist. J Rehabil Res Dev. 2009;46(2):277-286. [PubMed: 19533541]. doi:10.1682/JRRD.2008.07.0083

27. Moy ML, Martinez CH, Kadri R, et al. Long-term effects of an internet-mediated pedometer-based walking program for chronic obstructive pulmonary disease: randomized controlled trial. J Med Internet Res. 2016;18(8):e215. [PubMed: 27502583]. doi:10.2196/jmir.5622

28. Iwakura M, Okura K, Shibata K, et al. Relationship between balance and physical activity measured by an activity monitor in elderly COPD patients. Int J Chronic Obstr Pulm Dis. 2016;11:1505-1514. [PubMed: 27445470]. doi:10.2147/COPD.S107936

29. NHS England. Five Year Forward View. Leeds: NHS England; 2014.

30. Llewellyn S, Procter R, Harvey G, Maniatopoulos G, Boyd A. Facilitating technology adoption in the NHS: negotiating the organisational and policy context - a qualitative study. Health Serv Deliv Res. 2014;2(23):1-132. [PubMed: 25642495]. doi:10.3310/hsdr02230

\section{Publish your work in this journal}

The International Journal of COPD is an international, peer-reviewed journal of therapeutics and pharmacology focusing on concise rapid reporting of clinical studies and reviews in COPD. Special focus is given to the pathophysiological processes underlying the disease, intervention programs, patient focused education, and self management protocols. This journal is indexed on PubMed Central, MedLine and CAS. The manuscript management system is completely online and includes a very quick and fair peer-review system, which is all easy to use. Visit http://www.dovepress.com/testimonials.php to read real quotes from published authors. 